\title{
P189: Development of on line continuous education programme in a tertiary care hospital of a developing country
}

S Singh

From 2nd International Conference on Prevention and Infection Control (ICPIC 2013)

Geneva, Switzerland. 25-28 June 2013

\section{Summary}

Training is an essential component of HAIs, wher IT can play a major role. The objective was to develop an e learning continuous education programme for knowledge and skill based competency building in infection control. An interview was conducted and an on line e learning module was developed by a team. It improved the participation of HCWs in training. The competency, knowledge, practices and updating of recent advances was impressive. Process, outcome indicators improved and it proved to be cost effective.

\section{Introduction}

Training with IT aid would be the call of the day.

\section{Objectives}

Develop an e learning continuous education programme in infection control.

\section{Methods}

An interview was conducted to understand the impact of continuous education class room sessions, Pilot study was conducted. Team was included towards programing and deveopment. Every staff will get a user id and a password. An article with $10 \mathrm{MCQs}$, was released by the in-service administrator, open for the staff for the period of two weeks. They can attempt MCQs and grade them simultaneously and do simlulation training.

\section{Results}

1344 nursing staff, $48 \%$ of the staff were able to attend the class room session. $38 \%$ of the lectures were missed. Important topics were missed by the staff. Skill based learning was appreciated more. $88 \%$ of staff felt that e-learning improved their knowledge, skills and practice. $76 \%$ felt it allows flexibility in attending the sessions. $91 \%$ of the staff have started attending. Quality indicators in infection control and nursing, staff's knowledge and skills had improved from $43 \%$ to $87 \%$. Hand washing compliance improved from $47 \%$ to $78 \%$ in the hospital after institution of e learning and continuous reminders. Cost towards training has reduced from Rs 7 lacs per annum to 1.5 lacs per annum.

\section{Conclusion}

There is a remarkable improvement in knowledge, competency and skills. Attendance, process, outcome and cost showed improvement.

\section{Disclosure of interest}

None declared.

Published: 20 June 2013

doi:10.1186/2047-2994-2-S1-P189

Cite this article as: Singh: P189: Development of on line continuous education programme in a tertiary care hospital of a developing country. Antimicrobial Resistance and Infection Control 2013 2(Suppl 1):P189.

Infection Control, Amrita Institute of Medical Sciences, Kochi, India 